2009-04

Nuclear and membrane expression of the angiogenesis regulator delta-like ligand 4 (DLL4) in normal and malignant human tissues.

Martinez, JC

http://hdl.handle.net/10026.1/10315

10.1111/j.1365-2559.2009.03279.x

Histopathology

All content in PEARL is protected by copyright law. Author manuscripts are made available in accordance with publisher policies. Please cite only the published version using the details provided on the item record or document. In the absence of an open licence (e.g. Creative Commons), permissions for further reuse of content should be sought from the publisher or author. 


\title{
Nuclear and membrane expression of the angiogenesis regulator delta-like ligand 4 (DLL4) in normal and malignant human tissues
}

\author{
Juan Carlos Martinez, Marcus M Müller, Helen Turley, Graham Steers, Ludovine Choteau, \\ Ji-Liang Li, ${ }^{1}$ Richard Sainson, ${ }^{1}$ Adrian L Harris, ${ }^{1}$ Francesco Pezzella \& Kevin C Gatter \\ CRUK Tumour Pathology Group, Nuffield Department of Clinical Laboratory Sciences, University of Oxford, Oxford, and \\ ${ }^{1}$ CRUK Molecular Oncology Laboratories, Weatherall Institute of Molecular Medicine, John Radcliffe Hospital, Oxford, UK
}

Date of submission 9 May 2008

Accepted for publication 26 October 2008

Martinez J C, Müller M M, Turley H, Steers G, Choteau L, Li J-L, Sainson R, Harris A L, Pezzella F \& Gatter K C (2009) Histopathology, 54, 598-606

\section{Nuclear and membrane expression of the angiogenesis regulator delta-like ligand 4 (DLL4) in normal and malignant human tissues}

Aims: Delta-like ligand 4 (DLL4) is one of five known Notch ligands in mammals and interacts predominantly with Notch 1 . DLL4 is induced by vascular endothelial growth factor (VEGF) and acts downstream of VEGF as a 'brake' on VEGF-induced vessel growth, forming an autoregulatory negative feedback loop inactivating VEGF. This action was believed to occur only in vascular development, raising hopes that DLL4 could be a specific drug target for controlling vessel growth in tumours and other pathological conditions. Our aim was to pursue this by raising a monoclonal antibody to the internal domain of DLL4 and assess its distribution in normal and malignant tissues in comparison with antibodies against the external domain of DLL4.

Methods and results: The anti-DLL4 monoclonal antibody was raised using conventional mouse hybridoma techniques. The antibody has been fully characterized by Western blotting and transfectant immunostaining. It has also been comprehensively compared with other antibodies against both the internal and external domains of DLL4. The antigen is widely expressed on human tissues not only on endothelium but also on epithelium and stromal cells. Indeed, in our comprehensive survey only pulmonary alveoli failed to express DLL4. Of a wide range of malignancies, most also expressed DLL4 on tumour cells with a predominantly cytoplasmic pattern, although a number also displayed nuclear positivity.

Conclusions: Contrary to previous beliefs, DLL4 is widely distributed in tissues other than vessels including many malignancies. Furthermore, the molecule is internalized on binding its receptor and often transported to the nucleus. These findings raise many interesting possibilities for further study of DLL4 and its potential as a therapeutic target.

Keywords: delta-like ligand 4, human tissues, nuclear relocation

Abbreviations: DAPI, 4',6-diamidino-2-phenylindole; DLL4, delta-like ligand 4; ECD, extracellular domain; HUVEC, human umbilical vein endothelial cells; ICD, intracellular domain; PMA, phorbol myristate acetate; PBS,

phosphate-buffered saline; VEGF, vascular endothelial growth factor

\section{Introduction}

The generation of new vessels by tumour cells (neoplastic angiogenesis) is a hallmark of cancer and provides

Address for correspondence: K C Gatter, Nuffield Department of Clinical Laboratory Sciences, University of Oxford, The John Radcliffe Hospital, Headley Way, Headington, Oxford OX3 9DU, UK.

e-mail: kevin.gatter@ndcls.ox.ac.uk oxygen and nutrients to allow tumour growth. ${ }^{1}$ Since vascular endothelial growth factor (VEGF) is the most potent inducer of vessel production, anti-angiogenic therapy has been oriented towards blocking VEGF and VEGF receptors. This has led to increased patient survival in some tumour types. ${ }^{2-4}$ However, some tumours do not respond to VEGF blockade, and others that initially respond later become resistant. ${ }^{5-7}$ 
The Notch signalling pathway is a well-known regulator of embryological development and many important cellular functions including vascular development. $^{8}$

There are four Notch receptors in mammals (Notch1 to Notch4) and five ligands (Jagged 1 and 2, and deltalike 1, 2 and 4). Ligand receptor interaction is followed by two successive proteolytic cleavages of Notch. This is followed by translocation of the intracellular domain of the Notch receptor into the nucleus, initiating its transactivation activity and regulating the expression of other genes. ${ }^{9}$

Recent studies have focused on one of the ligands of the Notch 1 receptor, delta-like ligand 4 (DLL4), which is induced by VEGF and acts downstream of VEGF as a 'brake' on VEGF-induced vessel growth, forming an autoregulatory negative feedback loop inactivating VEGF ${ }^{10-12}$ Three different experimental systems, retinal development in the mouse eye, zebrafish embryos and tumours implanted in mice, have shown that Notch inhibition is followed by an increase of sprouting and branching of new vessels in association with gradients of VEGF protein. In contrast, VEGF blockade by pharmacological or genetic inactivation induces reduction of DLL4 expression and vessel sprouting, indicating that the Notch pathway acts downstream of VEGF. ${ }^{10-16}$

It has been shown that DLL4 is a potential drug target. Administration of a neutralizing DLL4 antibody or a recombinant DLL4 protein, aimed at blocking the Notch-DLL4 pathway, delayed tumour growth in mice. ${ }^{13,14}$ In keeping with studies on zebrafish embryos and mouse retina, blockade of DLL4 expression induced an increase of sprouting and branching of vessels, leading to an increase of vascular density in tumours. However, functional studies reveal that these newly formed vessels were inefficient and not connected to the vascular network of the tumours, resulting in inhibition of tumour growth.

DLL4 blockade has been shown to be effective in the treatment of VEGF-resistant tumours. ${ }^{13,14}$ Moreover, in addition to the antitumoral action of DLL4 alone, combined treatment with anti-VEGF has been shown to be more efficient in tumour growth control. ${ }^{13}$

The next step is to address whether these observations in experimental animal systems can be extrapolated to human neoplasia. For that aim, a prerequisite is the development of good antibodies capable of identifying DLL4 protein expression in human tissues, especially in routinely fixed and processed human specimens.

This study was undertaken to generate a monoclonal antibody against human DLL4 and to characterize its distribution and expression in normal, reactive and neoplastic human tissues in order to gain insight into the biological functions of DLL4 protein in normal, reactive and neoplastic development.

\section{Materials and methods}

PRODUCTION OF MONOCLONAL ANTIBODY

The D4/37 antihuman monoclonal antibody was generated against the intracellular domain (ICD) of human DLL4, by means of a recombinant DLL4 protein expressed in Escherichia coli, as described previously. ${ }^{17}$ Monoclonal antibodies were raised using conventional mouse methods.

\section{OTHER ANTIBODIES}

The expression and characterization of the D4/37 monoclonal antibody raised against the ICD of DLL4 was performed in in vitro studies and in human tissue biopsy specimens of different neoplastic and reactive conditions. This study was combined with parallel immunocytochemistry with the R3 polyclonal antibody targeting the DLL4 ICD $^{17}$ and with one commercially available polyclonal antibody against the extracellular domain (ECD) of DLL4 (Ab7280; Abcam, Cambridge, UK). These two antibodies were used as cross controls for DLL4 protein expression signal specificity. The antimacrophage monoclonal antibody KP1 against CD68 (Dako A/S, Glostrup, Denmark) was also used.

\section{TRANSFECTANTS}

Full-length hDLL4ECD and DLL4ICD were cloned into a pcDNA3.1 vector and the corresponding expression vector was transfected into the Chinese hamster ovary cell line with the Fugene 6 transfection reagent.

\section{CELL CULTURE}

Human cell lines A549, MDA468, SKBr3, K562, MCF7, U87 and U937 were prepared under both normoxic and hypoxic conditions as previously described. ${ }^{17,18}$

The U937 human histiocytic lymphoma cell line was used to analyse the possible role of phorbol myristate acetate (PMA) as an inducible agent of DLL4 in macrophages.

\section{IMMUNOFLUORESCENCE}

Cytospins of cell lines were made using a Shandon cytocentrifuge (Thermo Fisher Inc., Waltham, MA 
USA). Frozen sections $(8 \mu \mathrm{m})$ were air dried and fixed in acetone for $10 \mathrm{~min}$ or in buffered formalin for $1 \mathrm{~min}$. Primary antibody was applied for $1 \mathrm{~h}$ for D4/37 and $2 \mathrm{~h}$ for Ab780 and washed for $5 \mathrm{~min}$ in phosphatebuffered saline (PBS). Fluorochrome-conjugated secondary antibodies [antimouse, IgM 488 (green), IgG 568 (red), diluted 1:100, and antirabbit, 568 (red) or 488 (green), diluted 1:100 (Alexa Fluor ${ }^{\circledR}$, Molecular Probes Inc., Oregon, USA)] were applied for $45 \mathrm{~min}$ and washed for $5 \mathrm{~min}$ in PBS. 4',6-Diamidino-2phenylindole (DAPI) nuclear stain was achieved by mounting in Dako fluorescent mounting medium, containing $2 \mu \mathrm{l}$ DAPI at $1 \mathrm{mg} / \mathrm{ml}$ (DAPI FluoroPure ${ }^{\mathrm{TM}}$ grade; Molecular Probes, Eugene, OR, USA), in $1 \mathrm{ml}$ of mountant. Slides were left in a cold darkroom overnight. Observation and image acquisition were performed with a Zeiss LSM510 confocal microscope.

\section{WESTERN BLOT ANALYSIS}

Western blot analysis was performed as described previously. ${ }^{19,20}$

\section{HUMAN TISSUE STUDIES}

\section{Material}

Biopsy specimens of human tumours were obtained from the Cellular Pathology Department, John Radcliffe Hospital (Oxford, UK) and used to construct multitissue arrays containing colorectal, kidney, lung and breast cancer, as well as normal tissue specimens. Brain tumour tissue arrays containing meningiomas, glioblastomas and oligodendroglial tumours were retrieved from the Department of Pathology, Hospital Universitario 12 de Octubre (Madrid, Spain). Formalin-fixed paraffin-embedded 4- $\mu \mathrm{m}$ tissue sections or tissue array sections were mounted onto Snowcoat X-tra MicroSlides.

\section{Immunohistochemistry}

Immunohistochemical reactivity was produced using the Dako Real EnVision rabbit/mouse method (Dako A/S). Reactive non-neoplastic tissue specimens from cases of tonsillitis, nephritis and reactive gliosis were used as a reference for DLL4 protein expression in nonneoplastic inflammatory/proliferative lesions. Incubation with an unrelated antibody was employed as a control of antigenic preservation and recovery.

In situ hybridization

Radioactive in situ hybridization was performed in paraffin tissue sections from 20 breast, 20 kidney and 10 bladder cancer specimens, according to the method developed by Poulsom et al. ${ }^{21}$ The cRNA probe for hybridization was a human DLL4 probe of $741 \mathrm{bp}$ length fragment S35 labelled, located from position 1775 to $2516 \mathrm{bp}$. A parallel set of consecutive serial sections was simultaneously hybridized with a $\beta$-actin probe 428 bases long, generated from the original pHFBA3' clone described by Ponte et al., ${ }^{22}$ slightly modified and kindly provided by Professor R. Poulsom.

After 20 days' exposure, sections were studied under bright and dark field conditions with an Olympus BX51 Photo-microscope. All images were captured with a charge-coupled device Olympus DP70 camera. Slides were examined under the microscope with bright and dark field illumination to compare tissue morphology and hybridization signals.

Ethical approval

Ethical approval was obtained in compliance with current European and British in situ hybridization laws and regulations for human tissues and tumours.

\section{Results}

DLL4 TRANSFECTANT CELL EXPERIMENTS (FIGURE 1)

Comparison of the antibodies (D4/37, R3 and Ab7280) showed that D4/37 and R3 stained only the ICD DLL4 transfectants, mainly in the cytoplasm but occasionally in the nucleus. The ECD DLL4-GFP transfectants did not show any staining. Ab7280, in contrast, did immunostain the ECD DLL4 transfectants but was negative on the ICD DLL4 transfectants (Figure 1).

\section{Immunocytochemistry}

Cell lines were tested after normal and hypoxic conditions of culture. In the cell line MCF10A, established from normal breast epithelium and expressing DLL4, immunoreactivity with Ab7280 was seen in both cytoplasm and nucleus, whereas D4/37 was located only in the cytoplasm. In MDA468 and SKBr3 breast carcinoma cell lines, the localization of DLL4 (both ICD and ECD) was cytoplasmic in normoxia. However after 8-10 h of culture under hypoxic conditions, in addition to DLL4 cytoplasmic expression, nuclear expression was observed as well.

To check the expression of DLL4 on histiocytic cells we immunostained U937 cells with D4/37 antibody before and after stimulation with PMA, which is known to induce histiocytic differentiation in these cells. Cytoplasmic expression of both DLL4 and the macrophage marker CD68 was weak on untreated cells. 

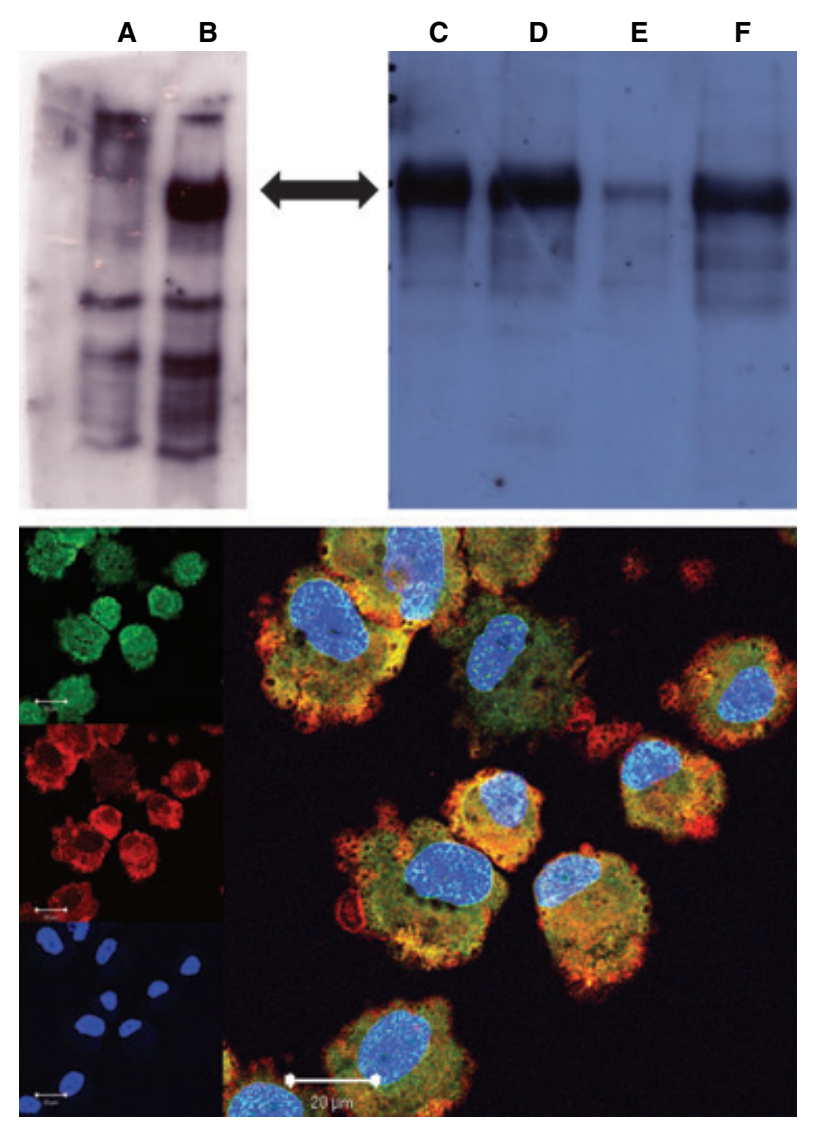

Figure 1. TOP: Western blots from U87 cells. A, U87 cell line with an empty vector i.e. DLL4 not transfected. B, U87 cell line transfected with DLL4 showing a band at the appropriate molecular weight for DLL4 (75-80 kD) - arrow. Western blots from kidney samples. C \& E, Two samples from normal kidney adjacent to tumours in D \& F. D \& F, Two samples from kidney tumours. Note the presence of a band for DLL4 at 75-80 kD in all renal samples (arrow). BOTTOM: Double immunostaining of HUVEC with antibody D4/37 (anti DLL4 ICD) in red and antibody Ab7280 (anti DLL4 ECD) in green. DAPI Nuclear stain (blue). Observe the cytoplasmic and nuclear DLL4 ECD expression with focal membrane cytoplasmic reinforcement and delineation of the nuclear membrane. There is also DLL4 ICD cytoplasmic staining which is focally stronger on the cytoplasmic membrane along with a weak granular nuclear signal in some cells. Cytoplasmic and focal membrane colocalization is seen in yellow in the main image on the right.

However, it was strongly expressed in the PMA-treated samples, with expression of CD68 (cytoplasmic) and DLL4 (cytoplasmic and nuclear) being dramatically increased.

Immunoreactivity in VEGF-treated human umbilical vein endothelial cells

Localization of both the ICD and ECD in untreated human umbilical vein endothelial cells (HUVEC) showed cytoplasmic DLL4 protein expression with a rim-like membranous pattern. Occasional mild nuclear expression was observed with both antibodies. After VEGF treatment of HUVEC, DLL4 cytoplasmic reactivity was increased with prominent nuclear expression.

By confocal microscopy, DLL4 ICD reactivity in both untreated and VEGF-treated HUVEC displayed moderate to intense cytoplasmic immunopositivity. A weak granular nuclear signal was observed in some cells. DLL4 ECD immunoreactivity was similar, but with a more intense granular nuclear positivity.

By double immunofluorescence staining followed by laser scanning confocal microscopy, colocalization of DLL4 ECD (Ab7280) and ICD (D4/37) was shown in the cytoplasm with areas of accentuation at the cell membrane.

\section{Western blotting}

Extracts of U87 DLL4 transfected cells and nonneoplastic and neoplastic kidney tissues displaying DLL4 protein expression by immunocytochemistry showed the presence of a $75-80-\mathrm{kD}$ band, corresponding to DLL4 protein with both D4/37 and Ab7280. Western blots from U87 cells that were not transfected with DLL4 were negative.

DLL4 EXPRESSION IN NON-NEOPLASTIC TISSUES (FIGURE 2)

Comparative analysis of DLL4 protein expression showed that all antibodies provided a similar pattern. As D4/37 was the most sensitive, detailed evaluation of DLL4 expression was undertaken with this antibody. Parallel immunohistochemistry with Ab7280 and R3 was used regularly as a control of specificity.

Widespread cytoplasmic and occasional nuclear DLL4 protein expression was observed in non-neoplastic tissue such as epidermal keratinocytes, dermal vessels and stromal cells in skin overlying breast cancer biopsy specimens. Reactive lymphoid tissue displayed strong DLL4 protein expression in germinal centres, highendothelial venules and occasional interfollicular cells. Neurons and reactive astrocytes of cortical areas infiltrated by neoplastic cells or from non-plastic gliotic scars also displayed DLL4 protein expression. DLL4 protein expression was also observed in non-plastic vessels, renal glomeruli and tubules and in breast lobules. Inflammatory cells were also shown to display DLL4 cytoplasmic and nuclear protein expression (Table 1).

DLL4 PROTEIN EXPRESSION IN HUMAN TUMOURS (FIGURE 2, TABLE 2)

DLL4 cytoplasmic protein expression by tumoral vessels was widely observed in all tumour types stained with 

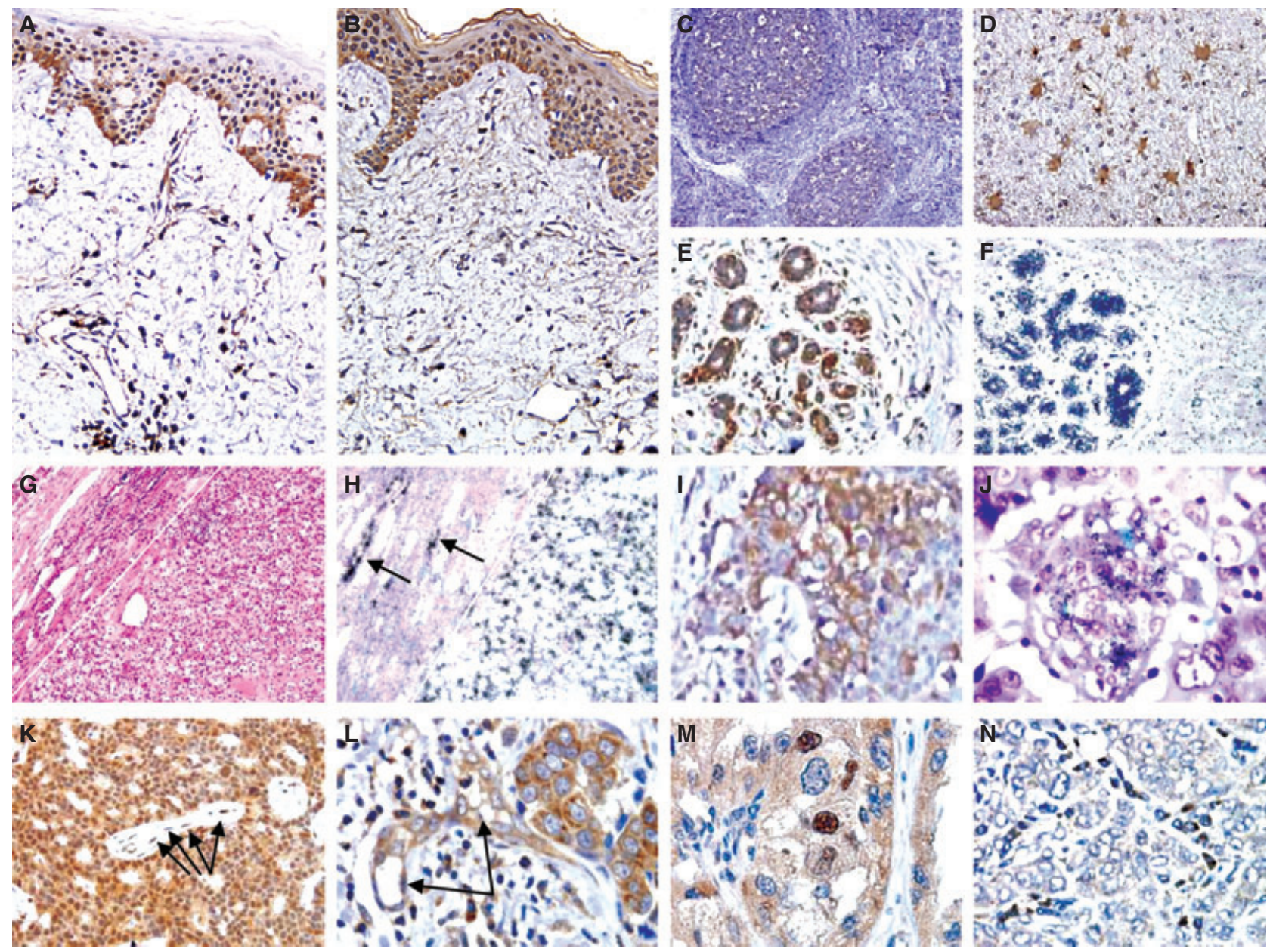

Figure 2. A, Normal skin - monoclonal D4/37 and B, Normal skin - polyclonal Ab 7280. Note the positive cytoplasmic and nuclear expression in the basal and middle layer keratinocytes, dermal vessels and perivascular infiltrates. The number of positive cells and the signal intensity is higher with D4/37. C, Germinal centre cells in a lymph node - monoclonal D4/37. D, Protoplasmic astrocytes in a gliotic scar - monoclonal D4/37. E, Normal breast lobular cells - monoclonal D4/37. F, Normal breast lobular cells - radioactive in-situ hybridization (RISH) on a serial section to E, Showing DLL4 mRNA expression. G, Renal clear cell carcinoma H\&E, Stroma to the left of and tumor to the right of the white line. H, Renal clear cell carcinoma serial section to (G) RISH showing DLL4 mRNA expression by tumor cells (right) and vessels (left-arrows). Stroma to the left of and tumor to the right of the white line. I, Breast cancer-antibody D4/37 shows cytoplasmic DLL4 protein expression on tumor cells. J, Breast cancer-RISH demonstrating mRNA expression in tumor cells. K, Breast cancer-antibody D4/37 demonstrates DLL4 cytoplasmic and nuclear protein expression by tumoral cells and by vessels within the tumor (arrow). L, Breast cancer-antibody D4/37 showing cytoplasmic expression of DLL4 protein by neoplastic cells and vessels (arrows) and nuclear and cytoplasmic expression by inflammatory cells in breast cancer. M, Renal cancer displaying weak cytoplasmic and strong nuclear DLL4 immunoexpression (antibody D4/37). N, Another renal cancer in which the tumor is negative but the associated inflammatory cells are positive for the expression of DLL4 (antibody D4/37).

the D4/37 monoclonal antibody. Reactivity varied within different tissues from weak to strong, although in any given specimen it was usually quite uniform. In general, positivity of vessels in the tumour was more marked than in surrounding stromal areas or in normal tissues.

DLL4 expression was also detected in non-endothelial structures. Neoplastic cells from the majority of the tumours studied displayed cytoplasmic DLL4 expres- sion of variable intensity, with areas of high expression versus others that were weakly positive or negative. Occasional positive nuclei were observed as well. Signal intensity was similar to that observed in vessels, varying from weak to strong. In individual samples there were areas of tumour cells with little or no expression alternating with those of strong positivity, whereas in vessels the expression was more uniform without significant variations in signal intensity. 
Table 1. The tissues on the array were scored if they showed positive (POS) or negative (NEG) staining in certain regions

\begin{tabular}{lll}
\hline Tissue & Score & Remarks \\
\hline Lymph node & POS & Germinal centres \\
\hline Adrenal & POS & $\begin{array}{l}\text { Fasciculata and reticularis } \\
\text { layers }\end{array}$ \\
\hline Breast & POS & Epithelium, vessels \\
\hline Salivary gland & POS & Epithelium \\
\hline Oesophagus & POS & Ductal epithelium, vessels \\
\hline Stomach & POS & Epithelium, vessels, stroma \\
\hline Pancreas & POS & Epithelium \\
\hline Large intestine & POS & Epithelium \\
\hline Appendix & POS & Epithelium, stroma \\
\hline Liver & POS & Hepatocytes, biliary ducts \\
\hline Brain (gliotic scar) & POS & Astrocytes, \\
\hline Trachea & POS & Epithelium, vessels, stroma \\
\hline Lung & NEG & Alveoli \\
\hline Kidney & POS & Tubules, glomeruli \\
\hline Cervix & POS & Stroma, vessels \\
\hline Endometrium & POS & Epithelium, vessels, stroma \\
\hline Ovary & POS & Stroma \\
\hline Testis & POS & Tubules, interstitial cells \\
\hline Amnion & Vessels \\
\hline Some & Stroma \\
\hline
\end{tabular}

Some remarks are added at the side. Every tissue was present twice or more on the multitissue array slides.

\section{IN SITU HYBRIDIZATION STUDIES}

DLL4 mRNA was expressed along intratumoral and non-tumoral vessels of different sizes in all cases $(20$ breast, 20 kidney cancer and 10 bladder cancer). At the cellular level, the distribution of silver grains clustered over endothelial cells of arterial vessels outlining the vascular network of neoplastic vessels as well as vessels of non-tumoral zones, although signal intensity was more intense in the neoplastic vessels.

Although the vasculature was the most prominent site of DLL4 expression by in situ hybridization, nonendothelial DLL4 expression was also observed. Neoplastic and inflammatory cells in 15 out of 20 breast,
16 out of 20 kidney and three out of 10 bladder cancers also displayed DLL4 mRNA expression. Clusters of silver grains lying over neoplastic nuclei and their surrounding cytoplasm were observed mainly around necrotic areas and in neoplastic foci infiltrating fat tissue in breast cancer, although with less intensity than that observed on vessels.

The pattern of expression was different from that seen on vascular cells. Instead of the linear distribution of silver grains observed over endothelial cells in both neoplastic and inflammatory cells, silver grains aggregated in clusters over the nuclei and surrounding areas of cytoplasm. Signal intensity varied between tumour areas from negative or slightly above background to an increased concentration of more densely packed silver grain clusters. Sparse accumulations of grains above or surrounding nuclei of inflammatory cells were frequently shown. DLL4 mRNA expression was also detected in non-neoplastic breast lobules included in some of the breast cancer biopsy specimens and in glomeruli adjacent to kidney cancer specimens as sparsely distributed clusters of silver grains.

\section{Discussion}

In this study, we generated a new monoclonal antibody against the internal domain of DLL4. The specificity is supported by in vitro studies of cell lines where D4/37 only stained cells transfected with the internal domain of DLL4. Western blotting reinforced the specificity of D4/37, showing that it recognized a $75-80-\mathrm{kD}$ band corresponding to DLL4 in extracts from transfected U87 cells. Further support comes from immunohistochemistry, which showed a similar pattern of reactivity with all three antibodies, including R3 against another internal domain antigen and Ab7280 against the external domain.

Immunohistochemistry of human tissues and tumours demonstrates that DLL4 protein expression is not restricted to endothelial cells, but is widespread in neoplastic as well as reactive tissues. These novel findings are supported by in situ hybridization studies that showed a similar distribution in normal and malignant tissues in endothelial, tumour, inflammatory and reactive cells. Another striking observation is that nuclear immunoreactivity was also clearly evident.

Until now the predominant view has been that DLL4 is an endothelial-specific Notch1 ligand that regulates vascular development. Indeed, DLL4 knockout mice die intra utero showing developmental vascular malformations. ${ }^{23}$ Similar findings have previously been observed in VEGF knockout mice. ${ }^{24}$ 


\begin{tabular}{|c|c|c|c|c|c|}
\hline \multirow[b]{2}{*}{ Cancer } & \multirow[b]{2}{*}{ Cases } & \multicolumn{2}{|c|}{ Cytoplasmic expression } & \multicolumn{2}{|c|}{ Nuclear expression } \\
\hline & & $\%(+) v e$ & Intensity & $\%(+) v e$ & Intensity \\
\hline Oligodendroglial & 84 & $81 / 84(97 \%)$ & $++/+++$ & $37 / 84(44 \%)$ & $+/++$ \\
\hline Glioblastomas & 20 & $20 / 20(100 \%)$ & $++/+++$ & $18 / 20(90 \%)$ & $+/++$ \\
\hline Meningiomas & 20 & $20 / 20(100 \%)$ & $++/+++$ & $5 / 20(25 \%)$ & $+/++$ \\
\hline Breast Ca & 110 & $86 / 110(78 \%)$ & $++/+++$ & $23 / 110(21 \%)$ & $+/++$ \\
\hline Kidney & 79 & $76 / 79(96 \%)$ & $++/+++$ & $72 / 79(91 \%)$ & $+/++$ \\
\hline Colorectal & 86 & $59 / 86(61 \%)$ & $++/+++$ & $11 / 86(13 \%)$ & $+/++$ \\
\hline Lung & 73 & $49 / 73(67 \%)$ & $++/+++$ & $14 / 86(16 \%)$ & $+/++$ \\
\hline
\end{tabular}

Table 2. DLL4 protein expression in different kind of tumours

$\%(+) v e$, percentage of positive cases; signal intensity: $(+)$, mild; $(++)$, moderate; $(+++)$, high.

Other cell types have previously been demonstrated to express DLL4 mRNA in embryological development. These include thymic and intestinal epithelium, neural tube, para-aortic bodies, optic recesses and nerves and developing retinal and olfactory cells. ${ }^{25}$ In addition, DLL4 mRNA expression has been observed on the neoplastic cells of glioblastomas. ${ }^{18}$ This suggests that DLL4 has other roles than solely regulation of vascular development.

Our study with antibodies D4/37 and Ab7280 against the DLL4 internal and external domain proteins combined with in situ hybridization for DLL4 mRNA has provided the following new findings:

1 DLL4 protein and mRNA expression is not restricted to endothelial cells. DLL4 expression in reactive conditions, e.g. neurons and astrocytes in reactive gliosis or by epithelial cells in nasal mucosa and skin adjacent to tumours, lymph node germinal centres or by neurons in areas invaded by neoplastic cells, is consistent with a biological role in processes other than vascular development and regulation. This is supported by a recent study showing that proinflammatory stimuli induce DLL4 protein expression in macrophages leading to amplification of the inflammatory response. ${ }^{26}$ Our results using PMA as an agent to induce DLL4 expression in U937 human histiocytic lymphoma cells support these findings. Moreover, DLL4 has been shown to play a role as a regulator of antiviral immunity. ${ }^{27}$ Furthermore, oscillating levels of DLL4 protein expression throughout the menstrual cycle have been reported in endometrial glandular cells. ${ }^{28}$

2 DLL4 protein may be expressed in nuclei, indicating nuclear translocation after activation and suggesting that DLL4 may have functional activity there.
Previous studies have shown that after DLL4 and Notch interact, the extracellular domains are cleaved and endocytosed by the ligand-expressing cell. ${ }^{29}$

Endocytosis has long been known as a cellular mechanism for nutrient capture, signal transduction and cell membrane composition. Recent studies have added to this by showing that it can also contribute to basic cellular organization mechanisms. By means of RNA interference studies, a high number of kinases have been shown to play a role in endocytosis, ${ }^{30}$ which links it to such cellular activities as cell cycle control, metabolism and cellular adhesion. ${ }^{31}$ In the present context, endocytosis of delta ligands is needed for Notch activation. ${ }^{32}$ Studies in flies have shown that delta ligands are located mainly in cytoplasmic vesicles ${ }^{33}$ and that endocytosis-defective delta ligands, although expressed at the cell surface, cannot activate Notch. ${ }^{34,35}$ It is known that internalized delta can be processed by the ubiquitin degradation pathway or activated and recycled to the plasma membrane, but nuclear translocation has also been proposed. ${ }^{29}$

Our finding of DLL4 nuclear expression could be the result of nuclear translocation. The fact that almost all previous studies on DLL4 expression have been addressed by in situ hybridization studies of DLL4 mRNA and not by protein localization may explain why this finding has not been previously documented. Findings such as this stress the importance of combined studies of gene product expression in order to establish a fuller picture of gene activation and function.

In conclusion, we have generated a robust and wellcharacterized monoclonal antibody allowing the study of the expression and possible function of DLL4 protein in human tissues that can be used in routine practice. Future studies are needed to address whether DLL4 has a role in patient stratification to guide treatment 
decisions that are currently directed towards DLL4 as a target of anti-angiogenic therapy to stop neoplastic growth. ${ }^{36-38}$ The expression in tumour cells should increase the relevance of these studies, as blocking this pathway with DLL4 inhibitors would have an impact not only on the tumour vasculature but also on the tumour cells themselves. ${ }^{18}$

\section{Acknowledgements}

Review of and comments on the in situ hybridization studies by Professors J. Bernal and Richard Poulsom were greatly appreciated. We thank Ms Irene MartinezIglesias for her contribution to the graphic work. Cancer Research UK, EU 6th Framework Grant Angiotargeting, and Fundación de Investigación Mutua Madrileña, Spain, supported this study.

\section{References}

1. Hanahan D, Weinberg RA. The hallmarks of cancer. Cell 2000; $100 ; 57-70$

2. Hurwitz H, Fehrenbacher L, Novotny W et al. Bevacizumab plus irinotecan, fluorouracil, and leucovorin for metastatic colorectal cancer. N. Engl. J. Med. 2004; 350; 2335-2342.

3. Laskin JJ, Sandler AB. First-line treatment for advanced nonsmall-cell lung cancer. Oncology 2005; 19; 1671-1676; discussion 8-80.

4. Ferrara N, Kerbel RS. Angiogenesis as a therapeutic target. Nature 2005; 438; 967-974.

5. Jain RK, Duda DG, Clark JW, Loeffler JS. Lessons from phase III clinical trials on anti-VEGF therapy for cancer. Nat. Clin. Pract. Oncol. 2006; 3; 24-40.

6. Casanovas O, Hicklin DJ, Bergers G, Hanahan D. Drug resistance by evasion of antiangiogenic targeting of VEGF signaling in latestage pancreatic islet tumors. Cancer Cell 2005; 8; 299-309.

7. Kerbel RS, Yu J, Tran J et al. Possible mechanisms of acquired resistance to anti-angiogenic drugs: implications for the use of combination therapy approaches. Cancer Metastasis Rev. 2001; 20; 79-86.

8. Radtke F, Schweisguth F, Pear W. The Notch 'gospel'. EMBO Rep. 2005; 6; 1120-1125.

9. Fortini ME. Gamma-secretase-mediated proteolysis in cell-surfacereceptor signalling. Nat. Rev. Mol. Cell Biol. 2002; 3; 673-684.

10. Lobov IB, Renard RA, Papadopoulos N et al. Delta-like ligand 4 (Dll4) is induced by VEGF as a negative regulator of angiogenic sprouting. Proc. Natl Acad. Sci. USA 2007; 104; 3219-3224.

11. Hellstrom M, Phng LK, Hofmann JJ et al. Dll4 signalling through Notch1 regulates formation of tip cells during angiogenesis. Nature 2007; 445; 776-780.

12. Suchting S, Freitas C, le Noble F et al. The Notch ligand Delta-like 4 negatively regulates endothelial tip cell formation and vessel branching. Proc. Natl. Acad. Sci. USA 2007; 104; 3225-3230.

13. Noguera-Troise I, Daly C, Papadopoulos NJ et al. Blockade of Dll4 inhibits tumor growth by promoting non-productive angiogenesis. Nature 2006; 444; 1032-1037.

14. Ridgway J, Zhang G, Wu Y et al. Inhibition of Dll4 signalling inhibits tumor growth by deregulating angiogenesis. Nature 2006; 444; 1083-1087.
15. Siekmann AF, Lawson ND. Notch signalling limits angiogenic cell behaviour in developing zebrafish arteries. Nature 2007; 445; 781-784.

16. Leslie JD, Ariza-McNaughton L, Bermange AL, McAdow R, Johnson SL, Lewis J. Endothelial signalling by the Notch ligand Delta-like 4 restricts angiogenesis. Development 2007; 134; 839844.

17. Williams CK, Li JL, Murga M, Harris AL, Tosato G. Up-regulation of the Notch ligand Delta-like 4 inhibits VEGF-induced endothelial cell function. Blood 2006; 107; 931-939.

18. Li JL, Sainson RC, Shi W et al. Delta-like 4 Notch ligand regulates tumor angiogenesis, improves tumor vascular function, and promotes tumor growth in vivo. Cancer Res. 2007; 67; 11244 11253.

19. Towbin H, Staehelin T, Gordon J. Electrophoretic transfer of proteins from polyacrylamide gels to nitrocellulose sheets: procedure and some applications. Proc. Natl Acad. Sci. USA 1979; 76; 4350-4354.

20. Burnette WN. "Western blotting": electrophoretic transfer of proteins from sodium dodecyl sulfate-polyacrylamide gels to unmodified nitrocellulose and radiographic detection with antibody and radioiodinated protein A. Anal. Biochem. 1981; 112; 195-203.

21. Poulsom R, Longcroft JM, Jeffery RE, Rogers LA, Steel JH. A robust method for isotopic riboprobe in situ hybridisation to localise mRNAs in routine pathology specimens. Eur. J. Histochem. 1998; 42; 121-132.

22. Ponte P, Gunning P, Blau H, Kedes L. Human actin genes are single copy for alpha-skeletal and alpha-cardiac actin but multicopy for beta- and gamma-cytoskeletal genes: $3^{\prime}$ untranslated regions are isotype specific but are conserved in evolution. Mol. Cell. Biol. 1983; 3; 1783-1791.

23. Gale NW, Dominguez MG, Noguera I et al. Haploinsufficiency of delta-like 4 ligand results in embryonic lethality due to major defects in arterial and vascular development. Proc. Natl Acad. Sci. USA 2004; 101; 15949-15954.

24. Ferrara N, Carver-Moore K, Chen H et al. Heterozygous embryonic lethality induced by targeted inactivation of the VEGF gene. Nature 1996; 380; 439-442.

25. Benedito R, Duarte A. Expression of Dll4 during mouse embryogenesis suggests multiple developmental roles. Gene Expr. Patterns 2005; 5; 750-755.

26. Fung E, Tang SM, Canner JP et al. Delta-like 4 induces notch signaling in macrophages: implications for inflammation. Circulation 2007; 115; 2948-2956.

27. Schaller MA, Neupane R, Rudd BD et al. Notch ligand Delta-like 4 regulates disease pathogenesis during respiratory viral infections by modulating Th2 cytokines. J. Exp. Med. 2007; 204; 2925-2934.

28. Mazella J, Liang S, Tseng L. Expression of Delta-like protein 4 in the human endometrium. Endocrinology 2008; 149; 15-19.

29. Ilagan MX, Kopan R. SnapShot: notch signaling pathway. Cell 2007; 128; 1246.

30. Pelkmans L, Fava E, Grabner $\mathrm{H}$ et al. Genome-wide analysis of human kinases in clathrin- and caveolae/raft-mediated endocytosis. Nature 2005; 436; 78-86.

31. Polo S, Di Fiore PP. Endocytosis conducts the cell signaling orchestra. Cell 2006; 124; 897-900.

32. Le Borgne R, Bardin A, Schweisguth F. The roles of receptor and ligand endocytosis in regulating Notch signaling. Development 2005; 132; 1751-1762.

33. Nichols JT, Miyamoto A, Weinmaster G. Notch signaling constantly on the move. Traffic 2007; 8; 959-969. 
34. Parks AL, Klueg KM, Stout JR, Muskavitch MA. Ligand endocytosis drives receptor dissociation and activation in the Notch pathway. Development 2000; 127; 1373-1385.

35. Itoh M, Kim CH, Palardy G et al. Mind bomb is a ubiquitin ligase that is essential for efficient activation of Notch signaling by Delta. Dev. Cell 2003; 4; 67-82.

36. Harrington LS, Sainson RC, Williams CK et al. Regulation of multiple angiogenic pathways by Dll4 and Notch in human umbilical vein endothelial cells. Microvasc. Res. 2008; 75; 144154.

37. Sainson RC, Harris AL. Anti-Dll4 therapy: can we block tumor growth by increasing angiogenesis? Trends Mol. Med. 2007; 13; 389-395.

38. Yan M, Plowman GD. Delta-like 4/Notch signaling and its therapeutic implications. Clin. Cancer Res. 2007; 13; 72437246. 